\title{
Distribución Geoespacial de los Espacios Públicos en el Distrito Central de Honduras
}

Celina Michelle Sosa Caballero

\section{Resumen}

El equilibrio territorial de la oferta cultural y recreativa de la ciudad del Distrito Central (Tegucigalpa y Comayagüela) y la clasificación de los espacios públicos según el tipo de administración, se analizan en el presente artículo, "Distribución Geospacial de los Espacios Públicos en el Distrito Central de Honduras", para conocer sobre la disponibilidad de éstos en base a los indicadores de la Agenda 21 Cultural.

Para cumplir con estos objetivos, metodológicamente, se ha hecho uso de las herramientas que proporcionan los softwares de sistemas de información geografía para analizar la concentración y dispersión de la infraestructura cultural, recreativa y deportiva en relación al centro de la ciudad y la clasificación de los espacios públicos según el tipo de administración (pública, privada y sin fines de lucro) para, generar los indicadores sobre la disponibilidad de los espacios públicos.

Del análisis de los mapas se concluye que la mayor parte de las instalaciones son deportivas, existiendo muy poca dotación de instalaciones culturales. Sobre la distribución geoespacial, hay tres tendencias, una, la ubicación de instalaciones deportivas se distribuyen por toda la ciudad, la otra, las instalaciones culturales se concentran en torno al centro de la ciudad y la tercera, la poca disponibilidad de parques y plazas residenciales donde los vecinos de una colonia o barrio puedan realizar sus actividades de recreación.

Palabra s Claves: Distribución Espacial, Espacios Públicos, Infraestructura cultural, Infraestructura Recreativa.

\section{Abstract}

The territorial balance of the recreational and cultural offer of the Distrito Central city (Tegucigalpa y Comayagua) and the classification of the public spaces according 
the administration type, are analyze in the article "Geospatial Distribution of the Public Spaces in the Distrito Central of Honduras", to now of the availability of the public spaces of the 21 Cultural Agenda.

To get to the objective, methodologically, with the tools of the softwares of geographic system information for analyze the concentration and dispersion of the cultural, recreation and sport infrastructure in relation to the center or the city to make the classification of the public spaces according the type of administration (public, privet and nonprofit) and with thar generate the indicators of the availability of public spaces.

Of the analysis of the maps concludes that the most part are sport installation, there are lees appropriations of cultural installation. About the geospatial distribution, there are three tendencies, one, the location of sport installation are distributed throughout the city, the cultural installation are concentrate in the center of the city and third, the limited availability of parks and residential places where residents of a neighborhood to make their recreation.

Keywords: Spatial Distribution, Public Spaces, Cultural infrastructure, Recreational Infrastructure.

Celina Michelle Sosa Caballero, (sosacelina@yahoo.com ) Departamento de Ciencia y Tecnologías de la Información Geográfica,Facultad de Ciencias Espaciales,Universidad Nacional Autónoma de Honduras - UNAH 


\section{Introducción}

El equilibrio territorial de la oferta cultural y recreativa de la ciudad del Distrito Central (Tegucigalpa y Comayagüela) y la clasificación de los espacios públicos según el tipo de administración, se analizan en el presente artículo, "Distribución Geospacial de los Espacios Públicos en el Distrito Central de Honduras", para conocer sobre la disponibilidad de los espacios públicos en base a la Agenda 21 Cultural.

En la Agenda 21 Cultural aprobada en mayo del 2004 por ciudades y gobiernos locales de todo el mundo, en el tema de cultura, sostenibilidad y territorio, se define los espacios públicos como: "espacios de cultura". Así mismo, en la Agenda de Ordenamiento Territorial del Concejo Centroamericano de Vivienda y Asentamientos Humanos -CCVAH- (2010), entre los principios se contempla la calidad del espacio público: "los espacios públicos son elementos esenciales para la vida, dinamismo, identidad y cultura de un asentamiento humano, razón por lo que estos deben ser diseñados y ubicados de forma que respondan a estas funciones. Deben articularse funcionalmente con la vivienda entre otros espacios, integrándose de tal forma que no se conviertan en lugares propicios para afectar la seguridad ciudadana".

Partiendo de los principios de que "la diversidad cultural es tan necesaria para la humanidad como la biodiversidad para la naturaleza; la diversidad de las expresiones culturales comporta riqueza y la importancia de un ecosistema cultural amplio, con diversidad de orígenes, agentes, contenidos y diálogo, convivencia e interculturalidad como principios básicos de la dinámica de relaciones ciudadanas" , contar con un análisis del equipamiento de la oferta cultural y recreativa del Distrito Central es un paso importante para mejorar las condiciones de habitabilidad urbana para el desarrollo personal de los ciudadanos.

En la literatura revisada se han identificado varias definiciones sobre espacios púbicos, la más general de ellas los define como: "los espacios públicos son bienes colectivos que pertenecen a todos los ciudadanos. Ningún individuo o grupo puede verse privado de su libre utilización, dentro del respeto a las normas adoptadas en cada ciudad" , de la que se destaca el principio de bien público de estos espacios.

Con el objetivo de analizar el equilibrio territorial de la oferta cultural y recreativa de la ciudad del Distrito Central de Honduras, el estudio se concentra en dos indicadores de la Agenda 21 cultural: en el tema de infraestructura cultural y 
prácticas culturales, se trabaja el indicador sobre diversidad de la oferta cultural y equipamientos y, en el tema de cultura, territorio y espacio público, el indicador sobre equilibrio territorial de la oferta cultural de la ciudad.

\section{Metodología}

A partir de la literatura revisada, se identificaron las categorías de clasificación de la infraestructura de espacios públicos de la ciudad del Distrito Central; las fuentes consultadas son: Sistema Nacional de Cultura, Informe Honduras de la Organización de Estados Iberoamericanos, , Mapa de Tegucigalpa sitios de interés del Instituto Hondureños de Turismo (sin fecha, ni escala); Informe de actividades 2010 Presupuesto y Plan de Trabajo - 2011 del Departamento de Deportes del AMDC, Google Earth, Google Mapas, Visitas de Campo.

Con la información obtenida de estas fuentes se crearon las bases de datos que contiene la clasificación de la infraestructura de los espacios públicos. Esta base se dividió en dos aspectos: una que maneja los datos geoespaciales (coordenadas UTM) de la infraestructura encontrada y la otra información del área en $\mathrm{m}^{2}$ que tiene la infraestructura deportiva.

Para el logro del objetivo se diseñó un procedimiento metodológico, que con la ayuda de herramientas de sistemas de información geográfica se pudiera hacer los cálculos y localización de las categorías que comprenden los indicadores de la Agenda 21 Cultural. El procedimiento consiste en las siguientes fases:

- Cálculo y representación cartográfica de los indicadores sobre la disponibilidad de espacios públicos en base a la Agenda 21 Cultural: Se realizó el cálculo de la distancia, con la herramienta buffer, usando como referente la plaza central para identificar el patrón de la dispersión-concentración de los tipos de instalaciones, para conocer la distancia de las instalaciones en relación al centro de la ciudad

- Análisis del equilibrio territorial de la oferta de los parques de la ciudad del Distrito Central de Honduras: Se hizo un cálculo con la herramienta buffer, de la distribución espacial de la infraestructura de los parques en relación a las aéreas de residencia de la ciudad.

- Análisis de la distribución de los Espacios Públicos de la Ciudad del Distrito Central de Honduras: Análisis de las categorías en que se ha clasificado la infraestructura según el tipo de actividad y su naturaleza pública, privada y sin fines de lucro. 


\section{Resultados}

Los resultados encontrados se han analizado en cinco categorías, la primera, característica y distribución de los espacios públicos de la ciudad del Distrito Central de Honduras donde se identifican el tipo de instalaciones de la infraestructura de espacios púbicos, la segunda, distancia en relación al centro de la ciudad donde se analiza la concentración y dispersión de la infraestructura cultural, recreativa y deportiva en relación al centro, la tercera, distribución de los parques en relación a las zonas residenciales donde se analiza la distancia existente entre los parques y las zonas residenciales, la cuarta, clasificación de la infraestructura de la oferta cultural y recreativa según tipo de administración donde se clasifica la infraestructura de los espacios públicos según el tipo de administración y la quinta, indicadores de la Agenda 21 Cultural, donde se analiza sobre la disponibilidad de los espacios públicos.

- Características y distribución geoespacial de los espacios públicos de la ciudad del Distrito Central de Honduras.

Se ha identificado y clasificado el tipo de instalaciones de la oferta cultural y recreativa de la ciudad, obteniendo un total de 365 instalaciones, donde el 31.51\% corresponde a canchas de baloncesto, el $22.74 \%$ corresponde a canchas de Fútbol de colonia o barrio, el $17.26 \%$ corresponde a canchas de futbolito privadas, y las instalaciones con valores relativos más bajos corresponden a canchas de beisbol, complejos deportivos, estadios, canchas privadas y teatros (ver tabla 1). 


\begin{tabular}{|l|r|r|}
\hline Tipo de Infraestructura & Absoluto & Relativo \\
\hline Bibliotecas & 15 & 4.11 \\
\hline Canchas de Fútbol de Colonia o Barrio & 83 & 22.74 \\
\hline Canchas de Futbolito Privadas & 63 & 17.26 \\
\hline Canchas de Béisbol & 2 & 0.55 \\
\hline Canchas de Baloncesto & 115 & 31.51 \\
\hline Canchas Privadas & 22 & 6.03 \\
\hline Cines & 7 & 1.92 \\
\hline Complejos Deportivos & 3 & 0.82 \\
\hline Estadios & 3 & 0.82 \\
\hline Museos & 13 & 3.56 \\
\hline Parques & 31 & 8.49 \\
\hline Áreas Protegidas & 3 & 0.82 \\
\hline Teatros & 5 & 1.37 \\
\hline Total & 365 & 100.00 \\
\hline Fuente: Elaboración Propia de Base de datos Marzo - Agosto 2013 & & \\
\hline
\end{tabular}

Tabla 1: Instalaciones del Equipamiento de la Oferta Cultural y Recreativa de la Ciudad del Distrito Central de Honduras 2013 - 2014

Fuente: Elaboración Propia de Base de datos Marzo - Agosto 2013

\section{- Distancia en relación al centro de la ciudad}

Utilizando herramienta Buffer proporcionadas por los softwares de sistemas de información geográfica se elaboró un mapa (ver mapa 1) para medir la distancia de las instalaciones culturales, recreativas y deportivas existentes en relación al centro de la ciudad, el punto de referencia es la Plaza Central de Tegucigalpa y el rango de medición de distancia, es de $1000 \mathrm{~m}$ a partir de este punto.

En el mapa se observa que la infraestructura cultural se concentra entre los 1000 y 4000 metros de distancia en relación al centro.

En la infraestructura recreativa existe una concentración entre los 1000 y 2000 metros de distancia en relación al centro, pero también hay otra concentración entre los 3000 y 5000 metros de distancia en relación al centro y una pequeña concentración en la zona suroeste.

La infraestructura deportiva se encuentra dispersa en toda la ciudad, siendo en su mayoría canchas de fútbol de barrios y colonias, canchas de baloncesto y canchas de futbolito.

Sobre la base de la distribución geoespacial, se identifican dos grandes tendencias: una de concentración de la infraestructura cultural y recreativa en torno al centro de la ciudad y la otra de dispersión de la infraestructura deportiva en toda el área urbana. 


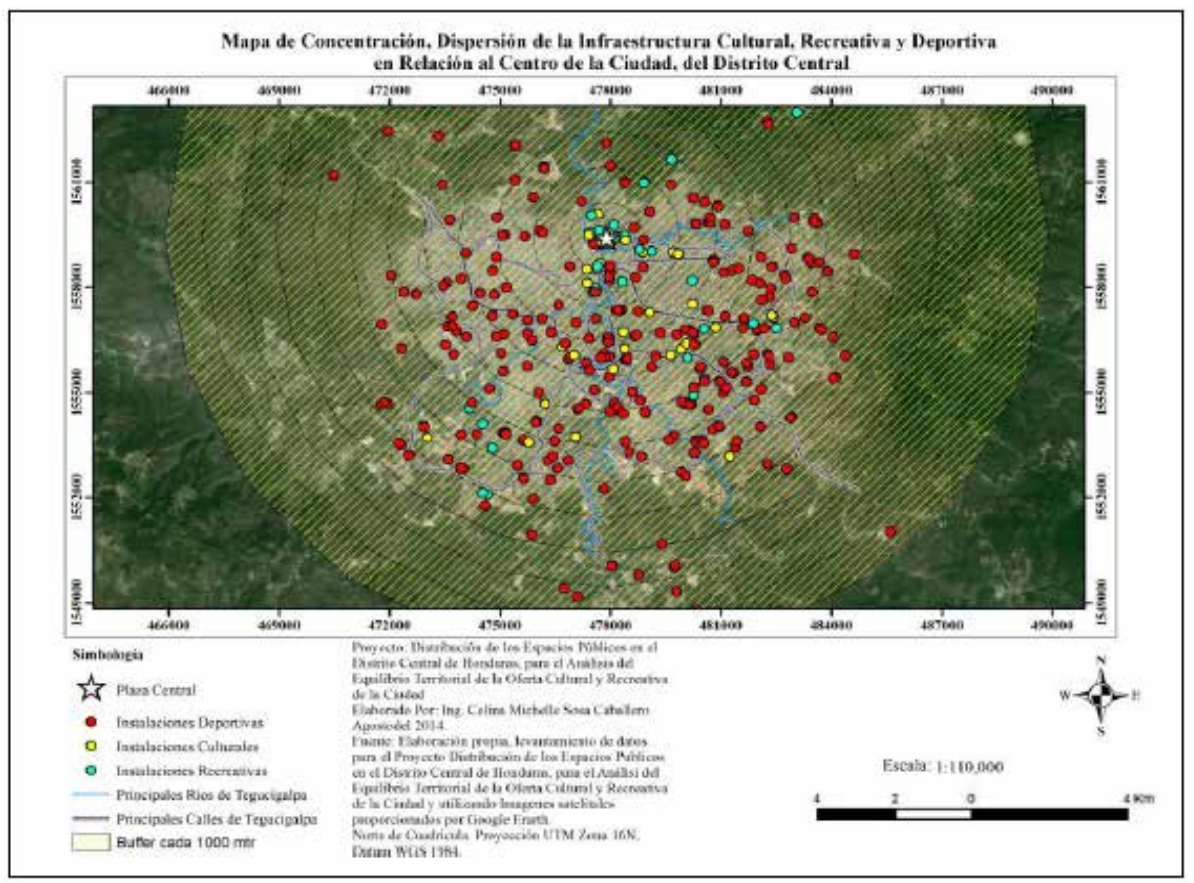

Mapa 1: Concentración, Dispersión de la Infraestructura Cultural, Recreativa y Deportiva en Relación al Centro de la Ciudad, del Distrito Central 2013 - 2014

\section{Concentración y dispersión de infraestructura de espacios públicos}

Utilizando la herramienta de Análisis de Cluster y de valor atípico (Anselin Local de Moran I) se elaboró un mapa (ver mapa 2) para realizar el análisis especifico de la concentración y dispersión de la infraestructura de los espacios públicos

De acuerda a esta herramienta se puede identificar cuatro patrones: 1) alta dispersión de infraestructura, 2) baja concentración de infraestructura, 3) media concentración de infraestructura y 4) alta concentración de infraestructura.

En el mapa se puede observar que la alta concentración de la infraestructura de espacios públicos se da a una distancia de $2000 \mathrm{~m}$ de la plaza central, por el contrario, se observa la alta 
dispersión de la mayoría de la infraestructura de espacios públicos localizado entre los $3000 \mathrm{~m}$ y 6000 de la plaza central.

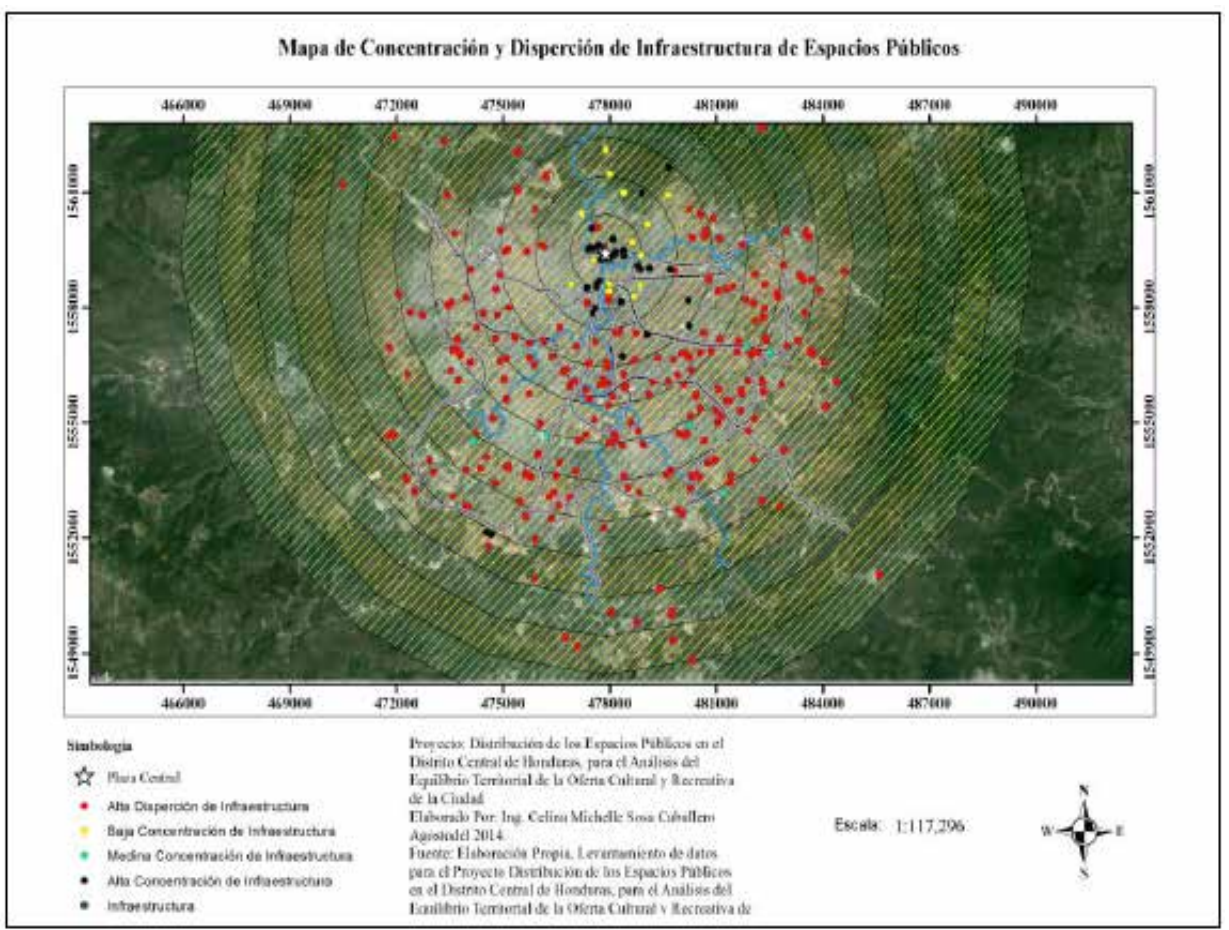

Mapa 2: Concentración y Dispersión de Infraestructura de Espacios Públicos 2013 - 2014

\section{- Distancia de los parques en relación a las zonas residenciales}

Utilizando la herramienta de buffer de los softwares SIG se elaboró un mapa (ver mapa 3) para medir la distancia de las instalaciones de los parques en relación a las zonas residenciales de la ciudad. Se usa el referente de $1000 \mathrm{~m}$ de distancia en relación a las residencias.

En el mapa se puede observar que la mayor concentración de los parques es en relación a la zona central de la ciudad, luego se puede ver otra concentración por la zona sureste de la ciudad pero siempre alrededor del centro y se puede ver una pequeña concentración en la zona sureste de la ciudad, el resto de las zonas residenciales no poseen este beneficio público. 


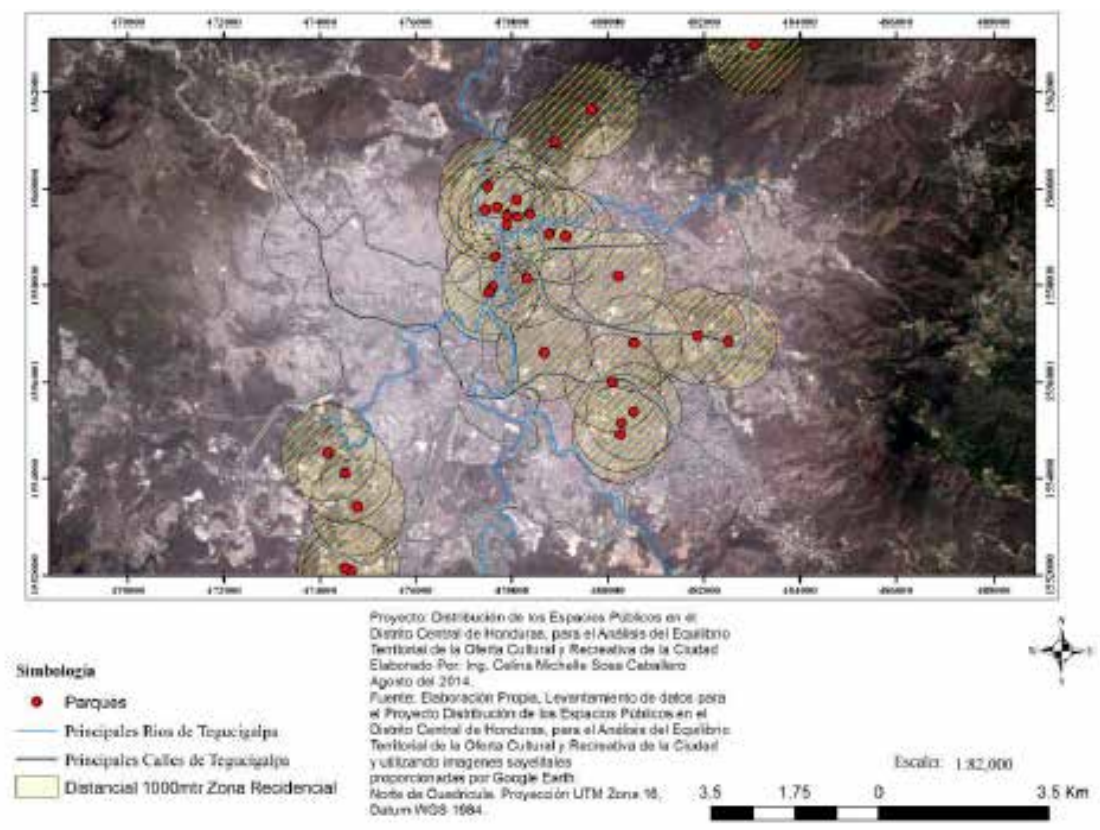

Mapa 3: Distancia de los Parques en Relación a las Zonas Residenciales 2013 - 2014

- Clasificación de la infraestructura de la oferta cultural y recreativa según tipo de administración (pública, privada y sin fines de lucro)

Se realizó un mapa de la infraestructura de los espacios públicos según el tipo de administración, la que se clasificó en tres categorias: pública, privada y sin fines de lucro, (ver mapa 4).

En el mapa se puede observar, que la mayoría de la infraestructura de los espacios públicos son administrados por un sector público, hay una parte importante de ellos que son administrados por un sector privado y son muy pocas las infraestructuras administradas por un sector sin fines de lucro. 


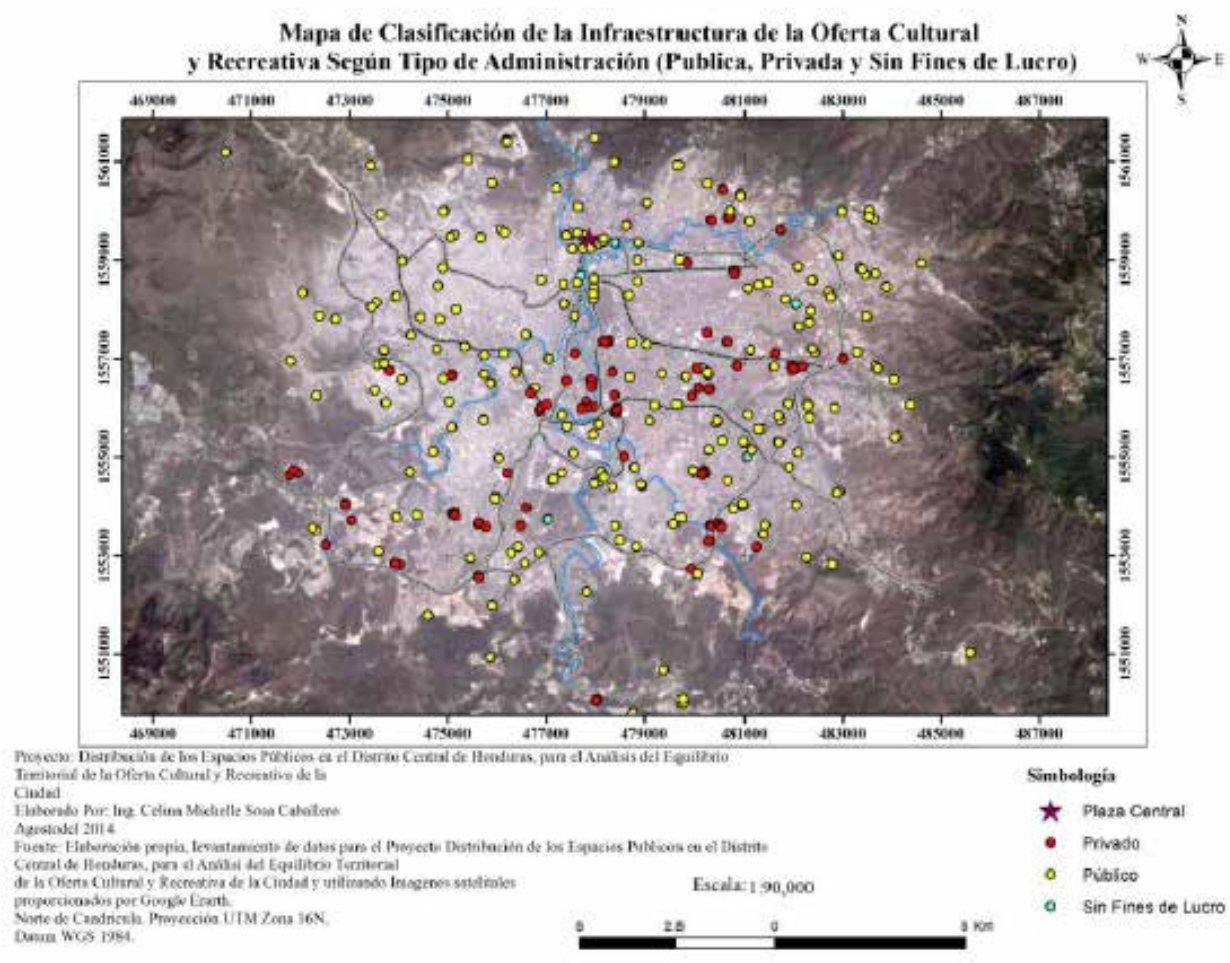

Mapa 4: Clasificación de la Infraestructura de la Oferta Cultural y Recreativa Según Tipo de Administración (Pública, Privada y Sin Fines de Lucro) 2013 - 2014

\section{- Indicadores de la agenda 21}

Con el objetivo de analizar el equilibrio territorial de la oferta cultural y recreativa de la ciudad del Distrito Central de Honduras, el estudio se concentra en dos indicadores de la Agenda 21 Cultural: en el tema de infraestructura cultural y prácticas culturales, se traba el indicador sobre diversidad de la oferta cultural y equipamiento y, en el tema de cultural, territorio y espacio público, el indicador sobre equilibrio territorial de la oferta cultural de la ciudad .

Indicador 1: Diversidad de la oferta cultural y deportiva. Los principales contribuyentes en la oferta cultural y deportiva son las instalaciones deportivas con $22.80 \%$ de Canchas de Fútbol de Colonia o Barrio; $17.31 \%$ con Canchas de Futbolito Privadas y $31.59 \%$ con Canchas de Baloncesto (ver Tabla No. 2). 
Indicador 2: equilibrio territorial de la oferta cultural y deportiva respecto de la distancia de las instalaciones en relación a la plaza central. Las concentraciones principales se dan entre los 4 y 7 mil metros de distancia de la plaza central de la ciudad, donde se concentra el $60.9 \%$ del total de instalaciones.

\begin{tabular}{|c|c|c|}
\hline Distancia respecto de la plaza central & Porcentaje de Instalaciones & Acumulados \\
\hline 1,000 & 8.5 & \multirow[t]{3}{*}{26.5} \\
\hline 2,000 & 8.8 & \\
\hline 3,000 & 9.2 & \\
\hline 4,000 & 17.6 & \multirow[t]{4}{*}{60.9} \\
\hline 5,000 & 16.9 & \\
\hline 6,000 & 14.4 & \\
\hline 7,000 & 12.0 & \\
\hline 8,000 & 5.6 & \multirow[t]{5}{*}{12.6} \\
\hline 9,000 & 4.6 & \\
\hline 10,000 & 1.4 & \\
\hline 11,000 & 0.4 & \\
\hline 12,000 & 0.7 & \\
\hline & 100.0 & 100 \\
\hline
\end{tabular}

Tabla 2: Número de Instalaciones y Distancia en Relación a la Plaza Central 2013 - 2014

Fuente: elaboración propia en base a base de datos en relación a los mapas de Distancia en Relación al Centro de la Ciudad

Nota: para este cálculo se han excluido los datos de las canchas de los Clubs privados.

Indicador 3: equilibrio territorial según el área de $\mathrm{m}^{2}$ de instalaciones de la oferta cultural y deportiva por habitantes. El cálculo de área destinada a instalaciones deportivas en relación a los habitantes de la ciudad en el 2013 y 2014, es una relación de menos de $1 \mathrm{~m}^{2}$ por habitante y el total del área de uso en deportes alcanza 1,18 $\mathrm{m}^{2}$. La referencia normativa encontrada es de $15 \mathrm{~m}^{2} / \mathrm{Hab}$. en el Plan de Ordenamiento Territorial de Pereira. Colombia 2012. 


\begin{tabular}{|l|r|r|}
\hline \multicolumn{1}{|c|}{ Instalaciones } & $\mathbf{m}^{2}$ & $\mathbf{m}^{2} / \mathrm{Hab}^{2}$ \\
\hline Parques & 811.830 .00 & 0.73 \\
\hline Canchas de futbolito privadas & 47.440 .75 & 0.04 \\
\hline Canchas clubs privados & 63.338 .00 & 0.05 \\
\hline Canchas baloncesto & 98.446 .00 & 0.08 \\
\hline Canchas futbol colonias y barrios & 279.958 .00 & 0.25 \\
\hline Total & $1,301.012 .06$ & 1.18 \\
\hline Población año 2013 & $1,101,942$ \\
\hline
\end{tabular}

Tabla 3: $\mathrm{m}^{2}$ de Instalaciones Deportivas por Habitantes 2013 - 2014

Fuente: elaboración propia en base a base de datos del cálculo del área de de las instalaciones con los softwares de sistemas de información geográfica.

El dato de población corresponde a la Encuentra de Hogares y Propósitos Múltiples 2013.

\section{Discusión}

De la primera aproximación a las características y distribución geoespacial de los espacios públicos de la ciudad del Distrito Central de Honduras se observa que la mayor parte de las instalaciones corresponden a las de tipo deportiva, donde las canchas de baloncesto y fútbol son mayoría, siendo relevante el dato de la poca dotación de instalaciones de tipo cultural como museos y teatros.

Como tendencia general, las instalaciones de las canchas de baloncesto, fútbol de barrio y las de futbolito están distribuidas en toda la ciudad y las instalaciones de tipo cultural están concentradas en torno al centro de la ciudad.

Si bien el déficit de espacios públicos de tipo cultural es muy importante, es necesario llamar la atención de la gravedad que supone la carencia de espacios de recreación en áreas residenciales, pues es en los parques y plazas de vecindario donde los niños pueden ir a jugar, los jóvenes, adultos y adultos mayores tienen un lugar para socializar, caminar y de recreación. En el caso del Distrito Central de Honduras, es evidente que la ciudad no brinda este servicio a los ciudadanos y son muy pocos los barrios o colonias que tienen el privilegio de acceder o contar con un parque 0 una plaza.

\section{Conclusiones}

En la literatura revisada se plantea que la oferta debe ser diversa y de múltiples expresiones, por ejemplo además de instalaciones deportivas la ciudad 
debe de ofrecer espacios culturales tales como: teatros, museos, parque, plazas, cines, bibliotecas o centros de documentación y parques, no obstante, en la ciudad del Distrito Central el $79.9 \%$ corresponde a instalaciones deportivas.

Otra premisa de la literatura es sobre la necesidad de una relación más estrecha entre los espacios públicos y los conjuntos habitacionales. En la ciudad del Distrito Central de Honduras esa relación existe principalmente con las canchas de fútbol de las colonias y barios y con las canchas de baloncesto dispersas en el perímetro urbano con vinculación directa a los barrios y colonias donde se encuentra ubicadas dichas instalaciones, mientras que la infraestructura cultural se concentra en el centro de la ciudad, donde el uso es más comercial que habitacional.

En esta aproximación al objeto de estudio y en relación al supuesto de trabajo, en el que se enuncia que el equipamiento de la oferta cultural y recreativa se concentra en áreas cercanas al centro de la ciudad, se identifican tres tendencias:

- Primero, las instalaciones culturales (teatros, bibliotecas, cines y museos), parques y plazas, se localizan en el centro de la ciudad y sus áreas circundantes.

- Segundo, las instalaciones deportivas están dispersas en toda el área urbanizada.

- Tercero, la ciudad no dispone de parques y plazas accesibles para los vecinos de barrios y colonias, siendo este un déficit muy importante porque supone que la gran mayoría de los habitantes de la ciudad no pueden disfrutar de un espacio público de esparcimiento.

\section{Bibliografía}

- Alcaldía Municipal del Distrito Central Departamento de Deportes. (2010). Informe de Actividades 2010, Presupuesto y Plan de Trabajo -2011. Tegucigalpa .

- AMDC/BID/EGI. (2000). Capitulo 6 Espacios Libres i Equipamiento Plan Territorial Tegucigalpa. 2000 - 2015. Tegucigalpa.

- Bolivar Galvis, A. M., Osorio, L. F., \& Lamprea, F. M. (2012). Espació Publicos y Calidad Urbana en Pereira Visión de una Nueva Ciudad. Obtenido de http:/l ribuc.ucp.edu.co:8080/jspui/bitstream/handle/10785/1262/Espacio_Publico_y_ Calidad_Urbana_en_Pereira.pdf?sequence=1 
- Borja, J., \& Muxí, Z. (2000). El Espacio Público, Ciudad y Ciudadania. Recuperado el 23 de Enero de 2013, de Pensar Contemporaneo: http://pensarcontemporaneo.files.wordpress.com/2009/06/el-espacio-publico-ciudad-y-ciudadania-jordi-borja.pdf

- Caballero Zeitun, E. L., \& Zelaya, M. (2009). Centros Comerciales un Nuevo Espacio de Encuentro: Privatización de los Espacios Públicos Áreas de Uso Público en lo Privado. Análisis Economico Posgrado Centroaméricano en Economía y Planificación del Desarrollo (POSCAE - UNAH) , 18 - 31.

- CCVAH. (2010). Agenda de Ordenamiento Territorial del Concejo Centroaméricano de Vivivenda y Asentamientos Humanos. El Salvador.

- Ciudades y Gobiernos Locales Unidos. (2006). Indicadores Culturales y Agenda 21 de la Cultura. Barcelona.

- Congreso Nacional de Honduras. (2006). Ley Marco del Desarrollo Integral de la Juventud. Recuperado el Febrero de 2013, de Poder Judicial de Honduras: http://www.poderjudicial.gob.hn/juris/Leyes/Ley\%20Marco\%20para\%20el\%20 Desarrollo\%20Integral\%20de\%20la\%20Juventud.pdf

- Instituto Hondureño de Turismo. (s.f.). Mapa Tegucigalpa Sitios de Interes. Tegucigalpa, Honduras.

- Instituto Nacional de Juventud. (2010). Politica Nacional de Juventud. Recuperado el 5 de Febrero de 2013, de Observatorio Social de la Descentralización desde Sociedad Civil: http://www.observatoriodescentralizacion.org/download/ pol\%C3\%ADticas_p\%C3\%BAblicas/Pol\%C3\%ADtica $\% 20$ Nacional $\% 20 \mathrm{de} \% 20$ la\%20Juventud\%200ficial.pdf

- Organización de Estados Iberoamericanos. (2011). Sistema Nacional de Cultura, Informe Honduras. Recuperado el 5 de Marzo de 2013, de Organización de Estados Iberoamericanos: http://www.oei.es/cultura2/honduras/cap7.htm\#2

- PNUD Informe . (2003). Informe de Desarrollo Humano - Honduras Capitulo 8 Un Nuevo Entorno Formal para la Cultura: Medio y Fin del Desarrollo Humano. Recuperado el 11 de Febrero de 2013, de UNDP: http://hdr.undp.org/es/informes/nacional/americalatinacaribe/honduras/honduras_2003_sp.pdf

- PNUD. (2009). Informe Sobre Desarrollo Humano - Honduras De la Exclusión Social a la Ciudadania Juvenil. Recuperado el 8 de Agosto de 2013, de UNDP: 
http://hdr.undp.org/es/informes/nacional/americalatinacaribe/honduras/INDH_ Honduras_2008-2009.pdf

- PNUD. (2006). Informe Sobre Desarrollo Humano - Honduras Hacia la Expansión de la Ciudadania. Recuperado el 6 de Junio de 2013, de UNDP: http://hdr. undp.org/en/reports/national/latinamericathecaribbean/honduras/2006_Honduras_web.pdf;

- Secretaria de Cultura Arte y Deportes. (2012). Objetivos Estrategicos. Recuperado el 5 de Mayo de 2013, de Secretaria de Cultura, Arte y Deporte: http://www. scad.gob.hn/index.php?option=com_content\&task=view\&id=15\&ltemid=64 